\title{
Long-term survival after cadaveric renal transplantation
}

\author{
E SAVDIE, J F MAHONY, R J CATERSON, J H STEWART, S ETHEREDGE， B G STOREY, \\ A G R SHEIL
}

\begin{abstract}
In a series of $\mathbf{4 0 4}$ consecutive first cadaver kidney transplants performed since 1967 the actuarial five- and 10year survival of patients were $61 \%$ and $47 \%$ respectively and of grafts $46 \%$ and $36 \%$. In more than four-fifths of the patients surviving these intervals the original cadaveric grafts were functioning at these times, and most of the remainder were sustained by subsequent grafts. Although graft survival has remained static since 1967, patient survival improved. Results for 43 consecutive second cadaver transplants were similar after five years to those of first grafts.
\end{abstract}

These results promote the acceptability of cadaveric transplantation as a long-term treatment for chronic renal failure.

\section{Introduction}

It is 30 years since the first attempts at human cadaveric renal transplantation, ${ }^{1-3}$ a procedure which became commonplace in the 1960s after the advent of safe and effective immunosuppressive therapy and dialysis support systems.

The number of kidney transplants performed in Australia continues to increase, such that in the year ended 31 October 1980 , there were 26 grafts performed per million population (compared with 14 per million in 1972), and 1362 patients, or 93 per million, were alive with functioning grafts. ${ }^{4}$ This latter figure is, per caput, equalled only by Denmark among 35 countries where patient registries are maintained, including the USA, UK, Japan, and all major Western European nations. ${ }^{5}$ Over $90 \%$ of the grafts performed in Australia have been from cadavers. ${ }^{4}$

This increasing activity, and its cost, ${ }^{6}{ }^{7}$ justifies an examination of the long-term outcome of the procedure in terms of mortality and graft survival and a comparison of contemporary with earlier results. Sydney Hospital began a programme of renal transplantation in 1967 and has performed as many kidney grafts as any other hospital in Australia. These transplants have been performed by a single surgical team and the patients supervised by only four physicians, and they thus provide uniform data suitable for long-term analysis.

\section{Patients and methods}

From August 1967 to December 1980404 first cadaver and 43 second cadaver renal allografts were performed on 404 patients (200 men, 204 women) by the department of transplant surgery at Sydney

\footnotetext{
Department of Medical Research, Kanematsu Memorial Institutes, Sydney Hospital, Sydney, NSW, Australia

E SAVDIE, FRACP, MRCP, renal physician

J F MAHONY, FRACP, director, renal unit

R J CATERSON, FRACP, renal physician

J H STEWART, FRCP, FRACP, former director, renal unit (present address: Department of Medicine, Westmead Centre, Westmead, Sydney, NSW, Australia)

S ETHEREDGE, MB, BS, renal registrar (present address: Renal Unit, San Francisco General Hospital, San Francisco, CA, USA)

B G STOREY, FRCS, FRACS, surgeon in organ transplantation

A G R SHEIL, MS, FRACS, professor and surgeon in charge of organ transplantation
}

Hospital. The causes of renal failure in this group included glomerulonephritis $(36 \%)$, analgesic nephropathy $(22 \%)$, reflux nephropathy $(12 \%)$, hypertension $(7 \%)$, and polycystic disease $(4 \%)$; only four patients had diabetic nephropathy, all receiving first cadaver grafts? The mean age was 39 years in recipients of both first (range 11-67) and second (range 17-53) grafts, and the average time spent on dialysis before transplantation by the first graft recipients was $11^{5}$ months. The only absolute contraindications to transplantation were⿷⿱ internal malignancy, chronic suppuration, and severe irreversible lungu disease. No patient was positive for hepatitis B surface antigen at the time of grafting.

Donor kidneys had warm ischaemia times of less than 60 minutesand were preserved either in ice after initial cold flushing (with eitherw Perfudex or hypertonic citrate ${ }^{8}$ solution) or by continuous hypothermig machine perfusion (after 1973). ${ }^{9}$ Recipients were computer selectedB for donor kidneys on the basis of HLA-A, B, and, from 1979, DR matching.

Renal allografts were positioned in the iliac fossa using standard surgical techniques ${ }^{10}$; prophylactic antibiotics were not administered during the period of study. Initial immunosuppression with azathio prine, prednisone, and actinomycin $\mathrm{C}$ was given as previously described. ${ }^{11}$ When possible, the dose of azathioprine was reducegg after five years from $3 \mathrm{mg} / \mathrm{kg}$ to $2 \mathrm{mg} / \mathrm{kg}$ and the prednisone given every other day. In acute rejection intravenous bolus methyl ? prednisolone $500-1000 \mathrm{mg}$ was given daily for one to three days, and the dose of oral prednisone was then gradually tapered to the pre-O rejection dose. As part of a clinical trial antilymphocyte globulin was? used in alternate patients from September 1968, and it was used ino all patients from $1972 .{ }^{11} 12$

From 1967 to 1969 blood transfusions were used liberally in our dialysis protocols, but after 1969 they were withheld before trans $\infty$ plantation unless strong clinical indications existed. A deliberate pre? transplant blood transfusion programme was not started untif September 1980 .

Survival was calculated actuarially by the life-table method of Cutler and Ederer. ${ }^{13}$ The effect of age on the outcome of first cadaven grafts and recipients was studied separately by comparing life tableફ for 140 patients aged less than 35, 142 aged 35-45, and 122 older than 45 years by the logrank method. ${ }^{14}$ Life tables for 118 first grafte performed from 1967 to 1970,121 performed from 1971 to 1974 , an $\bar{B}$ 110 done from 1975 to 1978 were also so compared. The mean age? of the patients transplanted in these three periods were not signifie cantly different $(37 \cdot 2 \pm 9 \cdot 8 ; 38 \cdot 8 \pm 9 \cdot 9$; and $38 \cdot 6 \pm 11 \cdot 8$ years respect ively), nor were the causes of their renal failure.

\section{Results}

Cumulative patient and first-graft survival after the original transplantation are depicted in fig 1 . After one, two, five, and 10 years patient survival was $79 \%, 72 \%, 61 \%$, and $47 \%$ respectively and graft survival $63 \%, 57 \%, 46 \%$, and $35 \%$.

Of 145 patients who had survived five years after their first graf 118 had functioning first grafts, 15 functioning second cadaverie. grafts, and two functioning third grafts at that time, leaving 10 or maintenance dialysis. Of 49 patients alive 10 years after their first graft, 44 had functioning first grafts, three second grafts, one ₹ु functioning third graft, and one patient was on dialysis.

The effects of age on patient and graft survival in the 404 recipiente are shown in figs 2 and 3. Patient survival for recipients aged unde 35 years was significantly greater than for those aged $35-45$ years and over 45 years after one $(p<0.05)$, five $(p<0.01)$, and $10(p<0.01)$ years (fig 2). Although the youngest age group also had the best grafo survival for every period (fig 3 ), this was statistically significant onlp at 10 years and only when compared with the over 45 age group $(p<0.05)$. There were no statistically significant differences in the life tables between those aged $35-45$ years and those aged over 45 years

Life tables for the first cadaver grafts performed in the three successive periods are shown in figs 4 and 5 . Patient survival afte grafts performed in 1975-8 was significantly greater than after those 
performed in 1967-70 and 1971-4 at one $(p<0.05$ and $p<0.01$ respectively), two $(p<0.01$ and $p<0.01)$, and five $(p<0.05$ and $p<0.01$ ) years after transplantation (fig 4 ). There were, however, no significant differences in the life tables for graft survival between the three groups (fig 5).

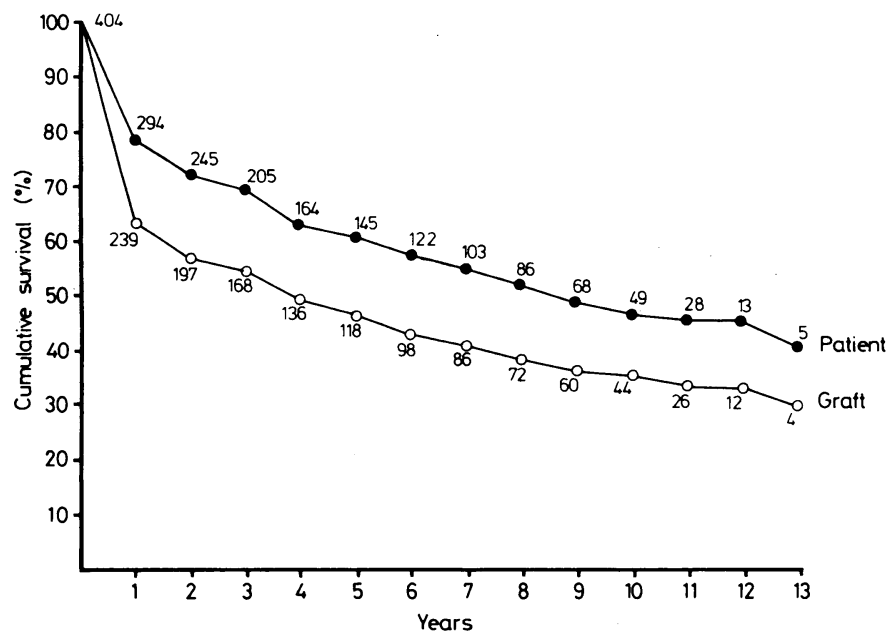

FIG 1-Life tables showing patient and graft survival after 404 first cadaver kidney transplants. Numbers of patients alive and grafts functioning at each period are shown.

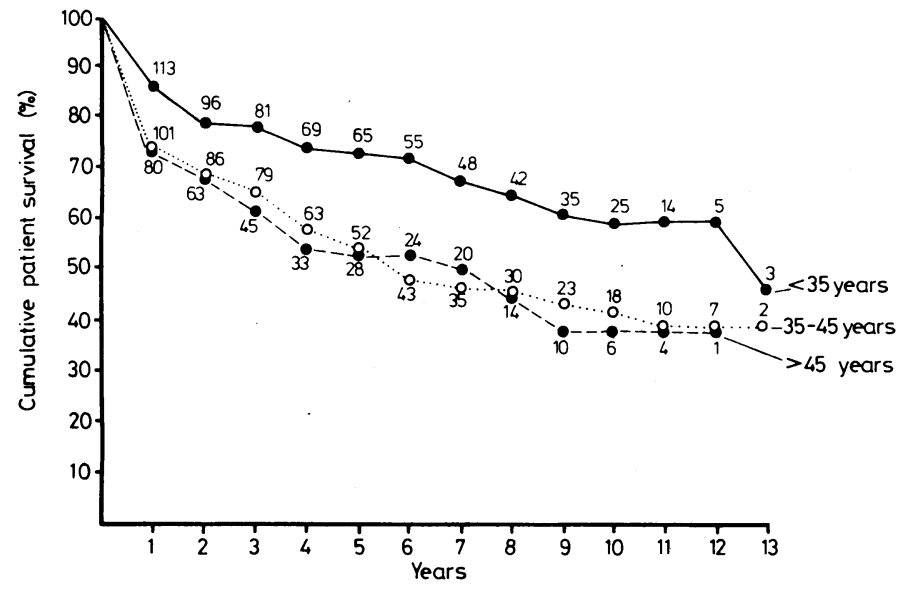

FIG 2-Life tables comparing patient survival after first transplantation for 140 patients under 35,142 aged $35-45$, and 122 older than 45 . Numbers of patients alive and grafts functioning at each period are shown.

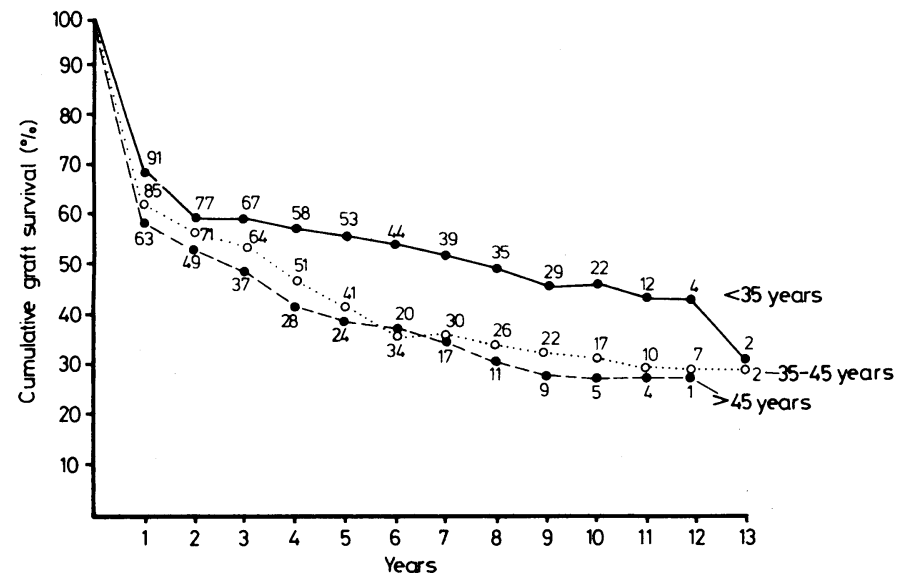

FIG 3-Life tables comparing graft survival after first transplantation for 140 patients aged under 35, 142 aged 35-45, and 122 older than 45 . Numbers of patients alive and grafts functioning at each period are shown.

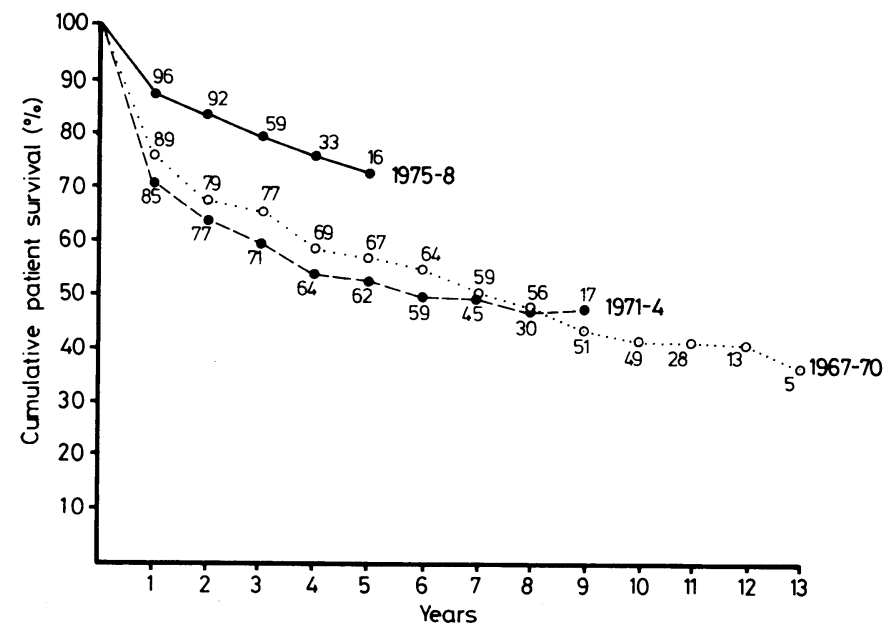

FIG 4-Life tables comparing patient survival after first transplantation for 118 grafts performed from 1967 to 1970,121 from 1971 to 1974 , and 110 from 1975 to 1978 . Numbers of patients alive and grafts functioning at each period are shown.

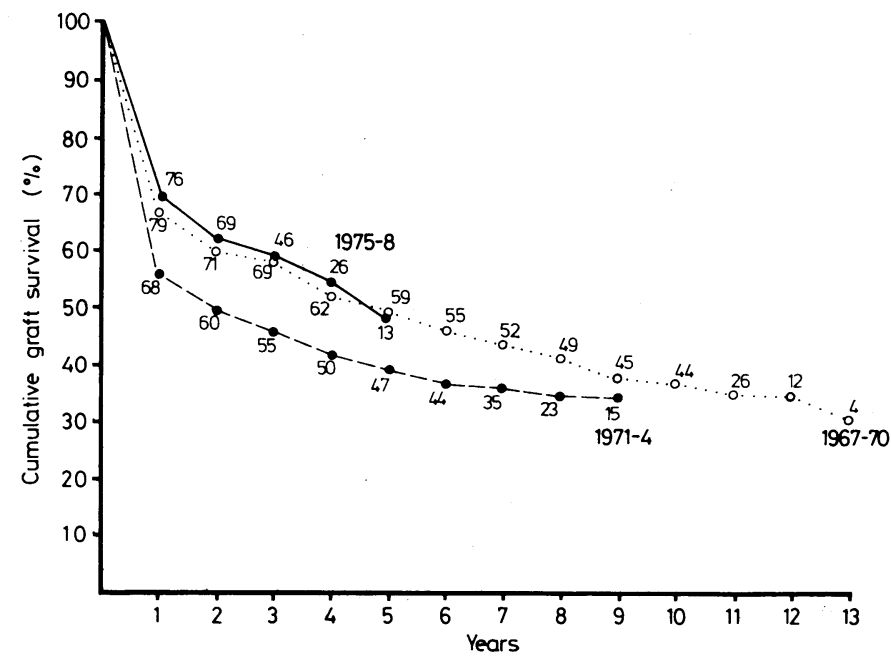

FIG 5-Life tables comparing graft survival after first transplantation for 118 grafts performed from 1967 to 1970,121 from 1971 to 1974 , and 110 from 1975 to 1978 . Numbers of patients alive and grafts functioning at each period are shown.

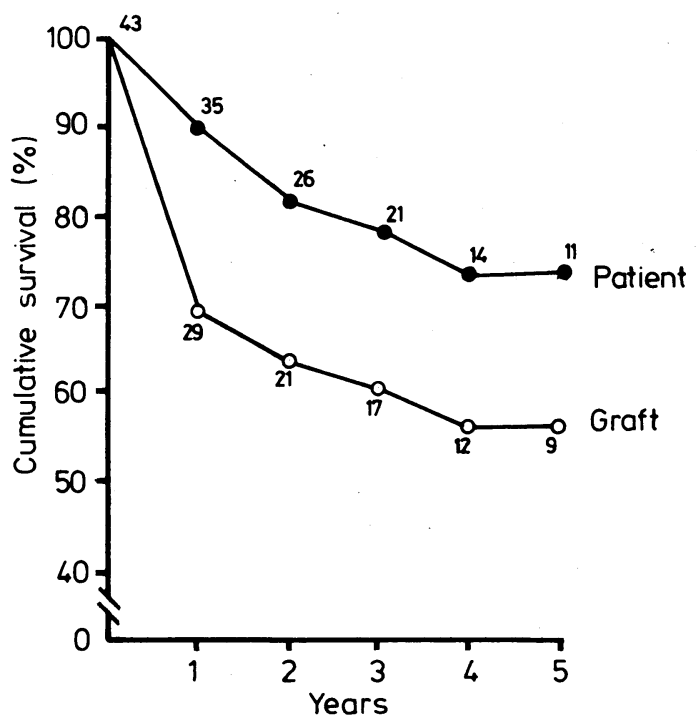

FIG 6-Life tables showing patient and graft survival after 43 second cadaver kidney transplants. Numbers of patients alive and grafts functioning at each period are shown. 
Cumulative patient and graft survival after transplantation of a second cadaveric graft are shown up to five years in fig 6 , the numbers being small after this time. Patient survival after one, two, and five years was $90 \%, 82 \%$, and $74 \%$ and graft survival $69 \%, 64 \%$, and $57 \%$ respectively. These results were not significantly different from those for the first grafts.

\section{Discussion}

This report documents the truly "long-term" outcome of first cadaveric kidney transplantation, data being available on a large number of patients up to 13 years after the time of grafting. These data show that, despite a continuing small attrition of both grafts and patients beyond the first two years (due mainly to vascular disease in our series), the five- and 10-year patient survival rates are acceptable, at $61 \%$ and $47 \%$ respectively, and that in more than four-fifths of these surviving patients their original grafts were still functioning at these times. These results were obtained during a period when blood transfusions were largely withheld.

There are few available long-term (10-year) series with which to compare our results. Recent analysis of nationwide (including Sydney Hospital) data by the Australian and New Zealand Dialysis and Transplant Registry (personal communication) showed very similar patient survival rates of $62 \%$ and $47 \%$ after five and 10 years respectively, but slightly worse graft survival rates of $41 \%$ and $29 \%$ (compared with $46 \%$ and $35 \%$ in our series). A single-unit series from Perth, Western Australia, of 147 recipients of first grafts showed almost identical long-term data as ours, ${ }^{15}$ while another from Edinburgh, Scotland, of 112 patients from a slightly earlier period reported patient and graft survival rates worse than those in our series. ${ }^{16}$

In our series transplantation was carried out as part of a community programme of integrated dialysis and transplantation $^{17}$ - that is, patients were started on dialysis, preferably at home,,$^{18}$ and received a transplant when a suitable cadaver kidney became available. In the case of graft failure the patient returned to dialysis to await a subsequent graft when medically fit. The patient survival rates so obtained compare favourably with those in patients treated by haemodialysis alone. They are slightly better than those for hospital dialysis $(53 \%$ and $36 \%$ survival at five and 10 years respectively) and slightly worse than those for home dialysis $(74 \%$ and $56 \%$ at five and 10 years respectively) in the largest series, which is that published by the European Dialysis and Transplant Association Registry, ${ }^{19}$ there being no Australian 10-year dialysis data yet available. Our patient survival rates have, however, significantly improved since 1975 and those transplanted since then are experiencing a five-year survival rate $(73 \%)$ equal to that of the European patients on home dialysis.

As in other large series, ${ }^{19}$ we have been able to show a favourable effect of youth on the outcome of transplantation. The major effect was a reduction in mortality in recipients aged less than 35 ; recipients aged $35-45$ had a similar mortality to those older than 45. The beneficial effect did not, however, extend to graft survival, there being little difference in the three life tables for the first few years after grafting, and it therefore cannot be inferred that the lower mortality in the young was a reflection of improved graft outcome. Only after 10 years was the graft survival statistically better in the youngest group, probably reflecting the compounding mortality in the older age groups rather than any basic difference in immunological tolerance.

We cannot enumerate precise factors responsible for the improvement in patient survival with the passage of time, reported here and noted by other authors. ${ }^{20-22}$ Like them, we believe that earlier graft recipients who had irreversible rejection were probably overimmunosuppressed in an effort to save the graft at all costs, and thus many more succumbed to infection, the principal cause of death during the first year after transplantation. Current policy dictates a prompt removal of the graft and return to dialysis should rejection be deemed irreversible on clinical or histological grounds.
The lack of significant improvement in graft survival since our programme began, also noted by others, ${ }^{20}$ is disappointing. Nevertheless, a one-year graft survival of $69 \%$ for $1975-8$, coupled with the one-year patient survival of $87 \%$, is encouraging, especially since patients in this series were not a highly $\frac{\varrho}{\overline{\bar{T}}}$ selected group. Restraints on the administration of blood through the 1970s may also have unfavourably biased graft $\mathbb{\Phi}$ survival for 1971-4 and 1975-8. The start of a prospective, m deliberate blood transfusion policy in September 1980 should $?$ improve graft survival in the near future. ${ }^{23}$ More selective $\overrightarrow{\overrightarrow{\vec{F}}}$ immunosuppressive regimens, such as the use of cyclosporin $\stackrel{0}{\rightarrow}$ $\mathrm{A}^{24}$ and the development of monoclonal antibodies against the various $\mathrm{T}$-cell subsets, ${ }^{25}$ may further improve graft and patient $\frac{\overline{\bar{T}}}{\overline{\mathrm{T}}}$ survival in the more distant future.

Our recipients of second cadaveric kidney grafts did as well $\stackrel{\varnothing}{\varrho}$ as those of first grafts, whereas in other series they have fared worse. ${ }^{19}$ The better results reported here may be due to selection. $\vec{\theta}$ In a sense patients who receive a second graft self-select themselves in that they survive the rigors of a failed first graft, make $\vec{\omega}$ a satisfactory return to an adequate haemodialysis schedule, $\stackrel{\mathcal{O}}{\mathcal{O}}$ elect to have another graft, and are deemed medically fit to do $\frac{5}{3}$ so by their doctors. In addition, our recipients of second grafts were selected after HLA matching and computer scoring. In of the last four years the scoring system has given heavy weighting of to B-locus identities, which, in Australian experience, favourably influence second graft survival for at least five years. ${ }^{26}$

Renal transplantation is a more satisfactory form of treatment $\vec{\overrightarrow{ }}$ than long-term dialysis for end-stage renal failure in that it offers patients the chance of better health and freedom from the $\frac{\text { o }}{2}$ dietary, physical, and logistic hindrances of repeated dialysis. N In Australia, for example, $82 \%$ of patients with a functioning 0 transplant are in full- or part-time work compared with $46 \%$ of those on dialysis. ${ }^{4}$ Transplantation also enables the treatment $\frac{}{\circ}$ of much greater numbers in renal replacement programmes with limited resources. Given the results reported here, we are $\vec{\varphi}$ concerned by the trend away from transplantation and towards dialysis in several countries, most noticeably the USA and $\square$ Japan. Whereas, in Australia the ratio of patients maintained by a functioning transplant to those maintained by dialysis is about $1: 1,4$ in the USA the ratio is $1: 3$ and in Japan $1: 17.5$ Moreover, there is a further tendency within these countries $\frac{0}{D}$ away from home and towards hospital dialysis, ${ }^{5}$ which has the poorest cost-effectiveness of any treatment for renal failure. ${ }^{7}$

There is little argument that an allograft from a suitable sibling or parent is the most successful way of treating end-stage chronic renal failure. Since these are infrequently available, however, cadaveric transplantation offers the only hope of full rehabilitation to most people with this disease. The results of this series show that in a large programme the long-term outcome $;$ of this procedure justifies the risks, which are diminishing with increasing experience, and vindicate the community support $\delta$ that transplantation has received in Australia. ${ }^{27}$

We thank the relatives of kidney donors who have made this programme possible and the nursing staff who have dedicated $\mathcal{N}$ themselves to it.

\section{References}

1 Servellé M, Soulie P, Rougeulle J, Delahaye G, Touche M. La greffe du rein. Rev de Chir Paris 1951;70:186.

2 Dubost C, Oeconomos N, Nenna A, Milliez P. Résultats d'une tentative de greffe rénale. Bull et mém Soc méd d hôp de Paris 1951;67:1372-82. @

${ }^{3}$ Hume DM, Merrill JP, Miller BF, Thorn GW. Experiences with renal homotransplantation in the human: report of nine cases. $\mathcal{f}$ Clin Invest homotransplantation $1955 ; 34: 327-82$.

4 Disney APS, ed. Fourth Report. Woodville, South Australia: Australian and New Zealand Combined Dialysis and Transplant Registry, 1981. $\overrightarrow{\mathbb{D}}$

5 Wing AJ, Selwood NH. Registry data, a collaborative exercise. In: 은 Zurukzoglu W, Papadimitriou M, Pyrpasopoulos M, Sion M, Zamboulis C, eds. Proceedings of the 8th International Congress of Nephrology, Athens, 1981. Basel, Switzerland: Karger, 1981:571-6.

6 Stewart JH, Topp ND, Martin S, et al. The cost of domiciliary maintenance haemodialysis. A comparison with alternative renal replacement regimens. Med f Aust 1973;1:156-9. 
7 Roberts SD, Maxwell DR, Gross TL. Cost-effective care of end-stage renal disease: a billion dollar question. Ann Int Med 1980;92:243-8.

${ }^{8}$ Ross H, Marshall VC, Escott ML. Seventy-two hour canine kidney preservation without continuous perfusion. Transplantation 1976;21: 498-501.

9 Sheil AGR, Drummond JM, Rogers JH, Boulas J, May J, Storey BG. A controlled clinical trial of machine perfusion of cadaveric donor renal allografts. Lancet 1975;ii :287-90.

10 Hume DM, Magee JH, Kauffman HM, Rittenbury MS, Prout Jr GR. Renal homotransplantation in man in modified recipients. Annals Surg 1963;158:608-44.

1 Sheil AGR, Mears D, Kelly GE, et al. Controlled clinical trial of antilymphocyte globulin in patients with renal allografts from cadaver donors, Lancet $1971 ; \mathrm{i}: 359-63$.

12 Sheil AGR, Kelly GE, Mears D, et al. Antilymphocyte globulin in patients with renal allografts from cadaver donors. Late results of a controlled trial. Lancet 1973 ;ii :227-8.

${ }^{13}$ Cutler SJ, Ederer F. Maximum utilization of the life-table method in analyzing survival. 7 Chron Dis 1958;8:699-712.

14 Peto R, Pike MC, Armitage P, et al. Design and analysis of randomized clinical trials requiring prolonged observation of each patient. II Analysis and Examples. Br $\mathcal{F}$ Cancer 1977;35:1-39.

${ }^{15}$ Hurst PE, Brockis JG, Dawkins RL, et al. Renal transplantation. 12-year experience. Med F Aust 1981;1:123-6.

16 Woodruff MFA, Nolan B, Anderton JL, Abouna GM, Morton JB, Jenkins AMcL. Long survival after renal transplantation in man. $\mathrm{Br} \mathcal{F}$ Surg 1976;63:85-101.

17 Sheil AGR, Stewart JH, Johnson JR, et al. Community treatment of endstage renal failure by dialysis and renal transplantation from cadaver donors. Lancet 1969 ;ii:917-20.
${ }^{18}$ Stewart JH, Gallery E, Charlesworth JA, et al. Home haemodialysis as part of a comprehensive renal replacement programme. Med $\mathcal{F}$ Aus $1973 ; \mathrm{i}: 153-5$.

19 Brynger H, Brunner FP, Chantler C, et al. Combined report on regular dialysis and transplantation in Europe, X, 1979. Proc Eur Dial Transplant Assoc 1980;17:2-86.

20 Tilney NL, Strom TB, Vineyard GC, Merrill JP. Factors contributing to the declining mortality rate in renal transplantation. $N$ Engl $\mathfrak{f}$ Med 1978;299:1321-5.

${ }^{21}$ Salvatierra O Jr, Feduska NJ, Cochrum KC, Najarian JS, Kountz SL, Belzer FO. The impact of 1000 renal transplants at one center. Ann Surg 1977;186:424-35.

${ }^{22}$ Corry RJ, Thompson JS, Freeman RM, Colville DS. Critical comparison of renal transplant survival between recipients of live related donor and cadaver organs. Surg Gynaecol Obstet 1978;146:519-23.

${ }^{23}$ Opelz G, Graver B, Terasaki PI. Induction of high kidney graft survival rate by multiple transfusion. Lancet $1981 ; \mathrm{i}: 1223-5$.

${ }^{24}$ Calne RY, Rolles K, White DJG, et al. Cyclosporin A initially as the only immunosuppressant in 34 recipients of cadaveric organs: 32 kidneys, 2 pancreases and 2 livers. Lancet 1979;ii:1033-6.

${ }^{25}$ Cosimi AB, Colvin RB, Burton RC, et al. Use of monoclonal antibodies to $\mathrm{T}$-cell subsets for immunological monitoring and treatment of recipients of renal allografts. $N$ Engl F Med $1981 ; 305: 308-14$.

26 Bashir HV, d'Apice A, on behalf of a subcommittee: Cadaveric renal transplantation and HLA matching in Australia 1971-1980. Transplantation (in press).

27 Smith T. Kidney transplants, doctors, and the media. $\mathrm{Br} M e d \mathcal{F} 1979$; : 182-3.

(Accepted 5 August 1982)

\author{
G P DUFFY
}

\begin{abstract}
Seventy-four patients with proved spontaneous subarachnoid haemorrhage were studied. Sixty-four underwent computed tomography and 55 underwent lumbar puncture. Seven cases deteriorated dramatically after lumbar puncture, six of these showing evidence of cerebral dislocation on further investigation. Four of the seven had not undergone computed tomography and three underwent computed tomography after lumbar puncture. Computed tomography of the brain could determine patients at risk of coning.

It is suggested that computed tomography is the investigation of choice after spontaneous subarachnoid haemorrhage and that lumbar puncture, if still then necessary, should be avoided until computed tomography has been undertaken.
\end{abstract}

\section{Introduction}

I attempted to assess the value and possible dangers of lumbar puncture after spontaneous subarachnoid haemorrhage and to assess the place of computed tomography in avoiding these dangers. The assessment was made as part of a survey of cases with subarachnoid haemorrhage admitted to the Royal Hobart Hospital over two years.

Department of Neurosurgery, Royal Hobart Hospital, Hobart, Tasmania 7000

G P DUFFY, FRCS, FRCPED, head of department

\section{Patients and methods}

Only patients who showed definite deterioration at the time of lumbar puncture, with the needle still in site, were considered to have reasonable presumptive evidence of deterioration related to the lumbar puncture. There were several patients whose continuing deterioration after lumbar puncture might have been related to the pathological changes of subarachnoid haemorrhage, but these cases were not included. Signs and symptoms before and after lumbar puncture were described by using the classification of Hunt and Hess. ${ }^{1}$

\section{Results}

A total of 74 cases with proved subarachnoid haemorrhage were admitted during the two years of the study. Sixty-three cases were admitted directly or indirectly into the department of neurosurgery and all of these underwent both computed tomography and angiography. The remaining 11 cases were treated in medical wards alone and only one of these underwent computed tomography. Fifty-five patients had lumbar puncture performed at some stage of their investigation and, though it was the policy in the neurosurgical unit to undertake lumbar puncture only if there was no evidence of haemorrhage on CT scan, in 44 cases lumbar puncture was undertaken before computed tomography.

Seven patients showed dramatic alteration in conscious and neurological state at the time of lumbar puncture. None of these had computed tomography before lumbar puncture. All underwent lumbar puncture within 12 hours of ictus. The table describes the change in classification after lumbar puncture, the diagnosis, and the ultimate outcome. The three survivors underwent operation for removal of clot, two for clipping of aneurysm, one angioma for partial excision. Necropsy undertaken in three of the four patients who died showed evidence of cerebral dislocation and tentorial and tonsillar coning. No necropsy was undertaken in the fourth, a patient who was conscious and alert with a dilated pupil at the time of lumbar puncture but who stopped breathing on the end of the needle. The three 